\title{
Avaliação de Usabilidade em Simuladores de Autômatos
}

\author{
${ }^{1}$ Mariana de A. Falcão, ${ }^{1}$ Axel V. G. Costa, ${ }^{1}$ Ramon W. S. Fonseca, ${ }^{1}$ Samuel Oliveira \\ de Azevedo, ${ }^{1}$ Welliana Benevides Ramalho
}

\author{
1Universidade Federal Rural do Semi-árido (UFERSA) \\ R. Gamaliel Martins Bezerra, 59515-000 - Angicos - RN - Brazil
}

\{marianadealbfalcao, axelvieira)@gmail.com, raamon.williams@ hotmail.com, \{samuel.azevedo, welliana.ramalho\}@ufersa.edu.br

Abstract. Due to the importance and complexity of the study of automata, simulators have been developed over time to assist in the learning and understanding of these automata. In order to have its objective met, it is necessary that these simulators present good usability. Considering this need, the present work proposes the use of tests to verify the usability of the software "Simulator of Automata", developed at the University of Uberaba (UNIUBE).

Resumo. Devido a importância e complexidade do estudo de autômatos, foram desenvolvidos, ao longo do tempo, simuladores para auxiliar na aprendizagem e entendimento desses autômatos. Para ter seu objetivo atendido, é necessário que estes simuladores apresentem boa usabilidade. Tendo em vista esta necessidade, o presente trabalho propõe o uso de testes para verificar a usabilidade do software "Simulador de Autômatos", desenvolvido na Universidade de Uberaba (UNIUBE).

\section{Introdução}

Autômatos fazem parte do nosso dia a dia, desde um simples relógio a um complexo algoritmo. O empenho em analisar os dispositivos da computação abstratos, denominados por "máquinas", se dá pela teoria dos autômatos. Eles funcionam de forma que exista uma entrada que pode ser chamada de letras ou símbolos. O conjunto delas formam uma sequência de letras que são chamadas de alfabeto (HOPCROFT; ULMAN; MOTWANI, 2002). Por fim, Sipser (1997) diz que o autômato faz a leitura desse alfabeto para verificar se é aceito ou rejeitado. Ele desempenha um papel importante na área da computação. É simples resolver problemas computacionais, pelo fato do sistema ser binário, assim como o resultado proporcionado por autômatos.

Para podermos compreender melhor sobre autômatos, foram criados alguns tipos de simuladores, os quais podem auxiliar os alunos durante o estudo. Alguns simuladores por sua vez não atendem completamente a necessidade do usuário, pois não possuem uma interface amigável, não tem manual de utilização, são incompletos ou até fazem um reconhecimento incorreto de informações (NUNES, 2017).

As falhas nos sistemas de autômatos pode comprometer o usuário e prejudicar seu entendimento sobre o assunto ou até deixá-lo frustrado por não conseguir utilizar o software corretamente. Por este motivo, o presente trabalho busca investigar a usabilidade do Simulador de Autômatos, desenvolvido por Ribeiro Júnior, Orbolato e Nepocumeno (2018) na Universidade de Uberaba (UNIUBE). Como resultado deste 
estudo propomos a utilização do método aqui descrito como forma de comparação com a usabilidade de outros simuladores.

\section{Fundamentação}

O Simulador de Autômatos da UNIUBE visa auxiliar a criação, simulação e conversão de modelos formais, tornando o aprendizado de linguagens formais e autômatos mais completo e eficiente. O software é capaz de reconhecer e simular os seguintes modelos:

- Autômatos Finitos Determinístos (AFD);

- Autômatos Finitos Não-Determinísticos (AFN);

- Autômatos com Pilha (AP);

- Máquinas de Turing (MT);

- Gramáticas Regulares (GR).

Além de disso, o Simulador também pode efetuar as conversões abaixo:

- $\mathrm{AFD}->\mathrm{AFN}$;

- $\mathrm{AF}->\mathrm{GR}$;

- $\mathrm{GR} \rightarrow \mathrm{AF}$.

Para avaliar este simulador, foram realizados testes de usabilidade. Esta é definida pela norma ISO/IEC 9126-1 como: “a capacidade de um software ser compreendido, aprendido, usado, atraente para seu utilizador, e estar em conformidade com as normas/orientações, quando utilizado sob condições especificadas”. Já para Nielsen (1993) a usabilidade tem como finalidade desenvolver interfaces que permitam uma interação fácil, agradável, com eficácia e eficiência.

Segundo Nielsen, citado por Barbosa (2010), esa usabilidade é um conjunto de cinco critérios descritos a seguir:

- Facilidade de aprendizado - o sistema deve ser simples de aprender, com pouco esforço por parte do usuário em realizar um procedimento;

- Eficiência - o sistema deve realizar uma tarefa de forma rápida e eficiente;

- Facilidade de recordação - o sistema deve requerer o mínimo de esforço cognitivo do usuário para lembrar como interagir com a interface do sistema, conforme aprendido anteriormente;

- Segurança no uso - o sistema deve buscar evitar problemas e auxiliar o usuário a se recuperar de situações críticas.;

- Satisfação - o sistema deve ser algo agradável ao usuário.

De acordo com Cybis (2003), o desenvolvimento de sistemas com boa usabilidade pode criar um impacto positivo na tarefa, no sentido da eficiência, eficácia e produtividade, permitindo ao usuário atingir seus objetivos com menos esforço e mais satisfação.

\section{Metodologia}

Para a realização deste trabalho, foram aplicados testes de usabilidade no Simulador de Autômatos. Segundo Barbosa (2010), este deve começar com um pré-teste para 
confirmar se o participante faz parte do público-alvo, seguido do processo de observação da interação do usuário com o software e, por fim, um pós-teste.

Estes testes tiveram caráter qualitativo e exploratório e foram divididos nessas etapas:

- Definição do público-alvo;

- Definição das tarefas;

- Elaboração do questionário;

- Aplicação do teste;

- Aplicação do questionário.

Foram definidos como público-alvo dos testes, estudantes e professores do curso de Bacharelado em Sistemas de Informação do campus Angicos da Universidade Federal Rural do Semi-árido (UFERSA). Uma vez que o Simulador de Autômatos foi desenvolvido para uso acadêmico. Logo após, foram definidas as atividades a serem aplicadas durante o teste. Os participantes deveriam resolver quatro questões. Dentre elas, três eram de fácil execução e uma de média.

Cinco pessoas (dentre elas, professores e alunos da UFERSA) participaram do teste de usabilidade. Antes de iniciar a aplicação das atividades, foi perguntado a cada um se eles já estudaram Teoria da Computação anteriormente, uma vez que sem o conhecimento prévio do assunto, não teriam condições de realizar o teste.

A aplicação da tarefa ocorreu em salas da UFERSA, onde o testador entrou em contato com o Simulador de Autômatos para resolver as quatro questões pré-estabelecidas. Após a aplicação do teste, foi entregue um questionário para que os usuários pudessem avaliar a qualidade do uso deste software. As perguntas presentes no questionário foram baseados na ISO/IEC 9126-1.

\section{Resultados e discussões}

O questionário aplicado durantes os teste contava com dezoito questões, suas perguntas tinham como principal propósito entender a experiência de uso dos entrevistados, destacando-se a usabilidade, operacionalidade, atratividade apreensibilidade, entre outras. As questões indagadas estão descritas a seguir:

1. Foi fácil aprender a usar esse software?

2. Quando eu cometo erros, é fácil corrigi-los?

10. O software fornece todas as informações necessárias para completar as tarefas?

3. É fácil simular autômatos usando esse software?

4. O software atendeu a minha necessidade?

11. Eu achei o software muito complicado de usar?

12. Os símbolos e ícones são claros e intuitivos?

5. É fácil lembrar como fazer as tarefas nesse software?

6. A organização do menu e dos comandos de ação é lógica, permitindo-os serem encontrados facilmente?

13. $\mathrm{Eu}$ achei o software desnecessariamente complexo?

14. A terminologia usada nos textos, rótulos etc. foi de fácil compreensão?

15. Eu precisaria do auxílio de outra pessoa para utilizar esse software.?

7. Consegui completar as tarefas com sucesso?

16. Eu achei frustrante usar esse software?

17. Eu recomendaria o uso deste simulador para outras pessoas?

8. Levei um tempo aceitável para concluir as minhas tarefas?

9. Eu gostei de usar esse simulador?

18. Eu considero o design agradável. 
Dentre as questões destacadas, foi possível observar que a maioria dos usuários concordam totalmente ou parcialmente com facilidade de aprender do software. Assim, como quando foram questionados quanto a facilidade em corrigir erros. Pode ser notado, através do questionário, que o software cumpre também a funcionalidade idealizada por ele. Foram destacados pontos positivos também quanto ao fornecimento de todas as informações necessárias para completar as tarefas, afirmando também uma facilidade de uso. Com relação ao design foi certificado que o simulador faz um bom uso dele, apresentando símbolos e ícones claros e intuitivos. Tais pontos, resultam nos entrevistados satisfação ao utilizar o software, cogitando até indicar a utilização do mesmo para outras pessoas.

\section{Conclusão}

O propósito inicial deste trabalho foi testar a usabilidade disposta no software Simulador de Autômatos, afim de comprovar sua eficiência e eficácia na criação simulação e conversão de modelos formais.

Como resultado dos testes aplicados foram obtidos respostas satisfatórias quanto ao nível de usabilidade simulador. Sendo assim, é adequado aplicar a mesma técnica utilizada nesta pesquisa em outros simuladores a fim de verificar a usabilidade como forma de garantir a aprendizagem linguagens formais e autômatos.

\section{References}

Barbosa, S. D. J.; Silva, B. S. (2010) "Interação Humano-Computador." Campus-Elsevier.

Cybis, W. (2003) "Engenharia de Usabilidade: Uma abordagem Ergonômica.”, UFSC, Florianópolis.

Hopcroft, J. E.; Ultman J. D.; Motwani, R. (2002) "Introdução à Teoria de Autômatos, Linguagens e Computação.", tradução da 2.ed: Vandenberg D.de Souza, Rio de Janeiro, Elsevier.

Ribeiro Junior, N. G. ; Orbolato, D. R. S.; Nepomuceno, R. M. Simulador de Autômatos. Disponível em: <http://www.simuladordeautomatos.com>. Acesso em: 19 nov. 2018.

NBR ISO/IEC 9126-1. (2007) "Engenharia de software - Qualidade de produto. Parte 1: Modelo de qualidade."

Nielsen, J. (1993) “Usability Engineering.”, Academic Press, Boston.

Nunes, C. (2017) "Simulador de Autômatos e Máquinas de Turing”, UFSC, Florianópolis.

Sipser, M. (1997) "Introduction to the Theory of Computation." 